\title{
Functional Analysis of Air Temperatures as Related to Chilling Requirements of Perennial Fruit Crops
}

\author{
Yao Xue, Sai Pavan Adigarla, Sravya Patil Bagli, Elmer Gray \\ Department of Agriculture and Public Health, Western Kentucky University, Bowling Green, KY, USA \\ Email: elmer.gray@wku.edu
}

How to cite this paper: Xue, Y., Adigarla, S.P., Bagli, S.P. and Gray, E. (2018) Functional Analysis of Air Temperatures as Related to Chilling Requirements of Perennial Fruit Crops. American Journal of Plant Sciences, 9, 561-570.

https://doi.org/10.4236/ajps.2018.94043

Received: November 18, 2017

Accepted: March 4, 2018

Published: March 7, 2018

Copyright $\odot 2018$ by authors and Scientific Research Publishing Inc. This work is licensed under the Creative Commons Attribution International License (CC BY 4.0).

http://creativecommons.org/licenses/by/4.0/

\begin{abstract}
After more than two centuries of observation and research on chilling requirements of perennial fruit crops, there remain unresolved aspects concerning relationships between chilling condition and ambient air temperatures. The purpose of this ongoing study was to further explain association between chilling temperature and plant functions: growing, chilling, and freezing. Temperature data consisted of 5-year averages for 50 Mesonet weather sites randomly located throughout Kentucky. Based upon the Chilling Hours Model analysis, available chilling hours exceeded requirements of commonly grown perennial fruit crops. In the extended study, max and min daily temperatures were processed separately permitting their comparisons within plant functional classes. Nearly twice as many min as max temperature days were included within the chilling class function. Most consecutive days of chilling temperatures ranged from 1 to 3 days and were more clustered with min than max temperatures. Using multiple-year averages especially when the temperatures were near freezing point, resulted in a high percentage of individual years with freezing temperatures that were not reflected in the group average. Separating max and min temperatures in functional classes permitted greater focus on critical temperature-chilling relations. Within the chilling range, impact of min on chilling was nearly twice that of max. Contrariwise, widely reported research literature confirms that global warming has greater influence on min than on max or mean temperatures.
\end{abstract}

\section{Keywords}

Chilling Hours, Diurnal Temperatures, Chilling Metrics, Global Warming 


\section{Chilling Is an Essential Process in Perennial Fruit Production}

Since Knight's 1801 report on breaking plant dormancy, more than two centuries of research and observation have provided a workable knowledge of the genetic and physiological processes involved [1] [2]. However, given the added challenges resulting from the great diversity of plants and their environments, the increase in human population, and the presence of global warming, the need to understand and manage dormancy continues to be a critical factor in perennial fruit and nut crops. Winter dormancy is both a fruit production and a survival requirement for these crops. During the chilling period the plant undergoes changes necessary for flower and fruit production in the following season. Specific temperature levels and duration are required to break the chilling period permitting resumption of normal growth in the spring. When chilling temperature requirements are not met, plants may produce irregular leaves and flowers resulting in reduced or no crop production.

\subsection{Chilling Models}

Commonly used models for quantifying winter chill are based upon hourly temperature records. Four models, among several, have gained acceptance due to ease of use and adaption to different environmental conditions [3].

1) Chilling Hours Model equates a chilling hour with a clock hour in which the air temperature is between $0^{\circ} \mathrm{C}$ and $7.2^{\circ} \mathrm{C}\left(32^{\circ} \mathrm{F}\right.$ and $\left.45^{\circ} \mathrm{F}\right)$. Freezing temperatures are not factored into winter chill calculation.

2) Utah Model is similar to Chilling Hour but assigns different chilling efficiencies to different temperature ranges.

3) Positive Utah Model is a modified version of the Utah developed for use in warmer climates.

4) The Dynamic Model postulates that chilling is a two-step process initiated by cool temperature and continuing into an intermediate product (chill portion) under warmer temperature.

\subsection{Comparability of Chilling Models}

Luedeling et al., (2009) [4] compared the four major models over 100 years of synthetic weather data. All models showed decrease in winter chill for all sites, but the extent of decrease varied with model. Luedeling and Brown (2011) [5] compared three models (Chilling Hours, Utah, and Dynamic) at 5078 weather stations around the world. The results varied substantially among models. The models were not proportional for chilling hours at different locations. They suggested need for conversion factors between winter chill models, and that further research efforts are needed to identify appropriate chilling models against the imminent effects of climate change.

\subsection{Temperature Measurements}

Hourly temperatures utilized in chilling models may be based upon recording 
schedules and statistical reporting units that affect validity of the outcome. Based upon testing of 12 climate models, Lobell et al. (2007) [11] found that weather change depended more upon changes in mean daily min or max than in combined daily means. Association between daily min was slightly greater than with daily max which was consistent with historical trends. Wilkens and Singh, (2001) [6] reported for quantities such as accumulated chill hours, response is different for min and max temperature as compared to mean daily temperature. Based upon global studies of maximum and minimum temperature trends, Easterling et al. (1997) [7] determined that daily minimum temperature is increasing at a faster rate or decreasing at a slower rate, than the daily maximum, resulting in a decrease in diurnal temperature range for many parts of the world.

Objectives of the extended study were 1) To analyze air temperatures by plant functions: growing, chilling, and freezing. 2) To compare the impact of daily max and min temperatures on chilling hour production, and 3) To explore the effect of duration and frequency of chilling days on chilling hour production.

\section{Materials and Methods}

The present treatise is an extension of the study reported by Xue et al. (2016) [8] and is based on the same data for years and sites. Site identification numbers are identical for both studies permitting cross referencing. Additional relevant information for both studies included local and international locations of sites, elevation, precipitation, air temperature, and chilling hour production.

In the second study, the highest hourly temperature for each day in the month was averaged to give the max temperature per month; the lowest hourly temperature for each day in the month was measured to give the min temperature per month. These max and min temperatures were classified into three functional ranges and related to chilling requirements as follows:

aa-Growing, both max and min above $7.2^{\circ} \mathrm{C}$; bb-chilling, both between $0^{\circ} \mathrm{C}$ and $7.2^{\circ} \mathrm{C}$; cc-freezing, both below $0^{\circ} \mathrm{C}$; ab-max above $7.2^{\circ} \mathrm{C}$, min between $0^{\circ} \mathrm{C}$ and $7.2^{\circ} \mathrm{C}$; ac-max above $7.2^{\circ} \mathrm{C}$, min below $0^{\circ} \mathrm{C}$; bc-max between $0^{\circ} \mathrm{C}$ and $7.2^{\circ} \mathrm{C}$, min below $0^{\circ} \mathrm{C}$. Homo classes ( $\mathrm{aa}, \mathrm{bb}, \mathrm{cc}$ ) indicate that both max and min temperature were within the same range; hetero classes $(a b, a c, b c)$ indicate that max and min temperature were in different ranges. Also, first and second letters specify max and min daily temperature; respectively. This classification system was applied to 5-year temperature means for each of the 50 Mesonet sites.

Linear correlation (Steel and Torrie, 1980) [9] was used to estimate relationships between chilling hour production (first study) and frequencies of max and min temperatures included in the different functional groups. For the bb chilling temperature range $\left(0^{\circ} \mathrm{C}-7.2^{\circ} \mathrm{C}\right)$, frequencies of inclusion of $\max$ and min were compared based on data for 8 months (September through April) at 11 sites (1, $5,10,15,20,25,30,35,40,45,50)$. For the $c c$, freezing temperature range (below $0^{\circ} \mathrm{C}$ ), which may kill flowers and fruit buds, frequency was based on individual years in addition to 5-year averages. 


\section{Results}

Temperature classification by plant function was applied to data from the 50 sites resulting in $26.8 \%$ aa, $1.2 \% \mathrm{bb}, 0.1 \% \mathrm{cc}, 36.2 \% \mathrm{ab}, 13.8 \% \mathrm{ac}$, and $22.0 \% \mathrm{bc}$ (Table 1). For the homo classes, aa days were most frequent reflecting the wider temperature range, $7.2^{\circ} \mathrm{C}$ and above. All the days in September and about one half of the days in October and April had max daily temperature in the aa range accounting for approximately one fourth $(26.8 \%)$ of the total days. The other two homo classes (bb and cc) included fewer max and min temperature days in their ranges. The bb range $\left(0^{\circ} \mathrm{C}-7.2^{\circ} \mathrm{C}\right)$ occurred between November and March and accounted for $1.2 \%$ of days. The cc class was lowest $(0.1 \%)$ indicating a near absence of days in which both max and min temperatures were below freezing $\left(0^{\circ} \mathrm{C}\right)$. Hetero classes $(a b, a c, b c)$ occurred more frequently reflecting the diurnal cycle. The ab class $\left(\max\right.$, above $7.2^{\circ} \mathrm{C}$, min between $\left.0^{\circ} \mathrm{C}-7.2^{\circ} \mathrm{C}\right)$ included more days than any class $(36.2 \%)$ and was most prevalent in November and March. Both hetero classes involving $\mathrm{c}$ were limited to November through March with the more frequent bc likely being more impacted than ac by diurnal fluctuations.

Average daily max and min temperature by month are presented in Table 2. Max and min temperatures had their highest average in September $\left(24.4^{\circ} \mathrm{C}\right.$ to $\left.13.3^{\circ} \mathrm{C}\right)$ and their lowest average in January $\left(5^{\circ} \mathrm{C}\right.$ and $\left.-2^{\circ} \mathrm{C}\right)$. Max and min temperatures by month were significantly correlated indicating that changes in one were positively associated with changes in the other.

Temperatures within the chilling range $\left(0^{\circ} \mathrm{C}-7.2^{\circ} \mathrm{C}\right)$ were further analyzed in relation to potential chilling hour production. Frequencies and durations of max and min temperatures within the chilling range were compared (Table 3). For the 242-day period, total chilling days (115.4) included 72.0 from min and 43.4 from max temperatures within the range. This relationship was present over single and multi-day (2, 3, 4 or more) durations.

Linear correlations based on data in Table 1 with 50 sites resulted in positive statistically significant $(\mathrm{P} \leq 0.05)$ coefficients between chilling hour production and frequencies of temperature classes aa $(\mathrm{r}=0.785)$, ab $(\mathrm{r}=0.207), \mathrm{ac}(\mathrm{r}=$ $0.342), b c(r=0.378)$ (Number of days in the bb and cc classes were insufficient for correlation analysis). A further analysis of data from 11 sites, resulted in positive significant coefficients between chilling hours and frequency of max temperatures in the $b$ range $(r=0.892)$, frequency of min temperature $(r=0.706)$ and combined $\mathrm{max} / \mathrm{min}$ temperatures $(\mathrm{r}=0.986)$. Correlation was generally higher between temperature within the chilling range than with the total range.

It was observed that class $c$ (freezing) occurred among some of the 5 years but was not apparent in the means for those years. Rather, the freezing temperature was masked by other years of larger, warmer temperatures. Since a single freezing temperature may kill developing buds, this phenomenon was explored using daily temperature in each of 5 months (December through April) for 5 years at 11 sites (Table 4). The results indicated that approximately $30 \%$ of individual 
Table 1. Functional classification of max and min daily temperature means for 8 months (September through April) over 5 years (2010-11 through 2014-15) at 50 Kentucky Mesonet sites ${ }^{1}$.

\begin{tabular}{|c|c|c|c|c|c|c|c|c|c|c|}
\hline \multirow{2}{*}{$\begin{array}{c}\text { Site } \\
\text { Number }\end{array}$} & \multirow{2}{*}{$\begin{array}{l}\text { County } \\
\text { Latitude }\end{array}$} & \multirow{2}{*}{$\begin{array}{l}\text { Coordinates } \\
\text { Longitude }\end{array}$} & \multicolumn{2}{|c|}{ Chilling hours } & \multicolumn{6}{|c|}{ Plant response code ${ }^{2}$} \\
\hline & & & & & aa & $\mathrm{bb}$ & $c c$ & $\mathrm{ab}$ & $\mathrm{ac}$ & $\mathrm{bc}$ \\
\hline 1 & Adair & 37.14 & -85.29 & 1552 & 69 & 6 & 0 & 95 & 30 & 42 \\
\hline 2 & Allen & 36.74 & -86.22 & 1464 & 81 & 7 & 0 & 92 & 32 & 30 \\
\hline 3 & Barren & 37.01 & -86.11 & 1527 & 68 & 7 & 0 & 98 & 32 & 37 \\
\hline 4 & Boone & 38.96 & -84.72 & 1508 & 65 & 3 & 3 & 77 & 12 & 82 \\
\hline 5 & Breathitt & 37.54 & -83.34 & 1680 & 49 & 3 & 0 & 94 & 57 & 39 \\
\hline 6 & Breckinridge & 37.71 & -86.49 & 1529 & 96 & 0 & 0 & 57 & 24 & 65 \\
\hline 7 & Bullitt & 37.92 & -85.66 & 1572 & 60 & 2 & 0 & 92 & 30 & 58 \\
\hline 8 & Caldwell & 37.1 & -87.86 & 1521 & 81 & 1 & 0 & 76 & 30 & 54 \\
\hline 9 & Calloway & 36.61 & -88.34 & 1499 & 83 & 4 & 0 & 81 & 31 & 43 \\
\hline 10 & Campbell & 39.01 & -84.47 & 1544 & 64 & 6 & 5 & 77 & 15 & 75 \\
\hline 11 & Carroll & 38.69 & -85.14 & 1632 & 58 & 2 & 1 & 85 & 27 & 69 \\
\hline 12 & Casey & 37.28 & -84.96 & 1595 & 52 & 3 & 0 & 99 & 41 & 47 \\
\hline 13 & Christian & 36.95 & -87.52 & 1463 & 81 & 2 & 0 & 81 & 26 & 52 \\
\hline 14 & Clark & 38.03 & -84.2 & 1579 & 61 & 4 & 1 & 91 & 27 & 58 \\
\hline 15 & Clinton & 36.71 & -85.13 & 1522 & 57 & 5 & 0 & 95 & 39 & 46 \\
\hline 16 & Crittenden & 37.38 & -88.04 & 1495 & 85 & 1 & 0 & 74 & 22 & 60 \\
\hline 17 & Cumberland & 36.8 & -85.43 & 1636 & 47 & 1 & 0 & 102 & 60 & 32 \\
\hline 18 & Fayette & 37.97 & -84.53 & 1555 & 70 & 1 & 0 & 83 & 19 & 69 \\
\hline 19 & Franklin & 38.12 & -84.88 & 1571 & 59 & 2 & 0 & 88 & 23 & 70 \\
\hline 20 & Fulton & 36.57 & -89.15 & 1526 & 97 & 4 & 0 & 69 & 37 & 35 \\
\hline 21 & Graves & 36.69 & -88.72 & 1519 & 67 & 1 & 0 & 91 & 36 & 47 \\
\hline 22 & Grayson & 37.46 & -86.34 & 1532 & 58 & 0 & 0 & 91 & 32 & 61 \\
\hline 23 & Hardin & 37.67 & -85.97 & 1573 & 65 & 0 & 0 & 85 & 28 & 64 \\
\hline 24 & Harrison & 38.49 & -84.34 & 1623 & 64 & 3 & 1 & 61 & 40 & 73 \\
\hline 25 & Henderson & 37.82 & -87.5 & 1571 & 59 & 4 & 2 & 77 & 39 & 61 \\
\hline 26 & Hopkins & 37.27 & -87.48 & 1468 & 78 & 0 & 0 & 86 & 22 & 56 \\
\hline 27 & Jackson & 37.36 & -83.97 & 1587 & 52 & 0 & 0 & 98 & 39 & 53 \\
\hline 28 & Johnson & 37.83 & -82.88 & 1662 & 42 & 0 & 0 & 92 & 57 & 51 \\
\hline 29 & Knott & 37.4 & -82.99 & 1474 & 74 & 12 & 0 & 92 & 24 & 40 \\
\hline 30 & Knox & 36.87 & -83.83 & 1613 & 55 & 1 & 0 & 100 & 49 & 37 \\
\hline 31 & Lewis & 38.58 & -83.42 & 1632 & 42 & 0 & 1 & 87 & 52 & 60 \\
\hline 32 & Lincoln & 37.58 & -84.62 & 1600 & 58 & 2 & 0 & 95 & 28 & 59 \\
\hline 33 & Logan & 36.85 & -86.92 & 1966 & 74 & 2 & 0 & 90 & 32 & 44 \\
\hline 34 & Madison & 37.72 & -84.15 & 1607 & 51 & 1 & 0 & 87 & 47 & 56 \\
\hline 35 & Marshall & 36.92 & -88.34 & 1499 & 82 & 1 & 0 & 78 & 37 & 44 \\
\hline 36 & Mason & 38.62 & -83.81 & 1595 & 56 & 4 & 1 & 88 & 22 & 71 \\
\hline 37 & McCreary & 36.77 & -84.47 & 1537 & 68 & 3 & 0 & 101 & 26 & 44 \\
\hline
\end{tabular}




\section{Continued}

\begin{tabular}{cccccccccccccc}
\hline 38 & Mclean & 37.59 & -87.32 & 1565 & 59 & 1 & 0 & 92 & 27 & 63 \\
39 & Mercer & 37.81 & -84.84 & 1533 & 63 & 2 & 0 & 91 & 25 & 61 & \\
40 & Metcalf & 36.98 & -85.7 & 1496 & 79 & 6 & 0 & 89 & 21 & 47 \\
41 & Morgan & 37.9 & -83.27 & 1594 & 64 & 2 & 0 & 82 & 41 & 53 \\
42 & Nicholas & 38.27 & -84.1 & 1590 & 54 & 2 & 1 & 94 & 20 & 71 \\
43 & Ohio & 37.46 & -86.86 & 1513 & 64 & 0 & 0 & 93 & 37 & 48 \\
44 & Owen & 38.55 & -84.74 & 1542 & 60 & 2 & 1 & 84 & 21 & 74 \\
45 & Owsley & 37.45 & -83.68 & 1627 & 52 & 2 & 0 & 90 & 54 & 44 \\
46 & Rowan & 38.22 & -83.48 & 1648 & 49 & 2 & 0 & 90 & 36 & 65 \\
47 & Taylor & 37.36 & -85.46 & 1580 & 56 & 3 & 0 & 95 & 36 & 52 \\
48 & Trigg & 36.82 & -87.86 & 1533 & 67 & 4 & 0 & 91 & 39 & 41 \\
49 & Union & 37.69 & -87.84 & 1533 & 66 & 12 & 0 & 94 & 16 & 54 \\
50 & Warren & 36.93 & -86.47 & 1549 & 72 & 5 & 0 & 91 & 29 & 45 \\
Mean & & & & 1577 & 65 & 3 & 0.3 & 8 & 33 & 53 \\
$\%$ & & & & 26.8 & 1.2 & 0.1 & 36.21 & 3.8 & 22.0 \\
\hline
\end{tabular}

${ }^{1}$ Far additional physiographical characteristics of sites, see Xue, Y., et al. (2016) [8]. ${ }^{2}$ Plant response code $\left({ }^{\circ} \mathrm{C}\right)$. aa-Growing, both max and min above $7.2^{\circ} \mathrm{C}$; bb-Chilling, both between $0^{\circ} \mathrm{C}$ and $7.2^{\circ} \mathrm{C}$. cc-Freezing, both below $0^{\circ} \mathrm{C}$; ab-max above $7.2^{\circ} \mathrm{C}$, min between $0{ }^{\circ} \mathrm{C}$ and $7.2^{\circ} \mathrm{C}$; ac-max above $7.2^{\circ} \mathrm{C}$, min below $0^{\circ} \mathrm{C}$; bc-max between $0^{\circ} \mathrm{C}$ and $7.2^{\circ} \mathrm{C}$, min below $0^{\circ} \mathrm{C}$.

Table 2. Mean number of days by classification of max and min air temperature responses for 5 years (2010-11 through 2014-15) at 50 Kentucky Mesonet sites.

\begin{tabular}{|c|c|c|c|c|c|c|c|c|c|c|c|}
\hline \multicolumn{12}{|c|}{ Mean number of days (24-hr period) within months } \\
\hline \multirow{2}{*}{ Response Class $^{1}$} & \multirow{2}{*}{ Sep } & \multirow{2}{*}{ Oct } & \multirow{2}{*}{ Nov } & \multirow{2}{*}{ Dec } & \multirow{2}{*}{ Jan } & \multirow{2}{*}{ Feb } & \multirow{2}{*}{ Mar } & \multirow{2}{*}{ Apr } & \multicolumn{2}{|c|}{ Yearly } & \multirow{2}{*}{ Range in \% over 50 sites } \\
\hline & & & & & & & & & Total & $3 \%$ & \\
\hline aa & 30 & 15.5 & 0.8 & 0.9 & 0.1 & 0.2 & 1 & 16.5 & 65 & 26.8 & $17.3-40.0$ \\
\hline $\mathrm{bb}$ & 0 & 0 & 0.3 & 1.8 & 0.4 & 0.2 & 0.1 & 0 & 2.8 & 1.2 & $0.0-4.9$ \\
\hline $\mathrm{cc}$ & 0 & 0 & 0 & 0 & 0.2 & 0.1 & 0 & 0 & 0.3 & 0.1 & $0.0-2.1$ \\
\hline $\mathrm{ab}$ & 0.1 & 15.6 & 20.1 & 9.5 & 2.1 & 3 & 23.8 & 13.5 & 87.7 & 36.2 & $23.6-42.1$ \\
\hline ac & 0 & 0 & 7.1 & 3.4 & 7.9 & 10.2 & 4.7 & 0 & 33.3 & 13.8 & $5.0-24.8$ \\
\hline \multirow[t]{2}{*}{$\mathrm{bc}$} & 0 & 0 & 1.2 & 15.4 & 20.7 & 14.8 & 1.6 & 0 & 53.7 & 22 & $8.7-33.9$ \\
\hline & \multicolumn{5}{|c|}{ Daily temperature $\left({ }^{\circ} \mathrm{C}\right)$} & & & & Mean & & Correlation (r) \\
\hline $\operatorname{Max}$ & 24 & 19 & 13 & 7 & 5 & 7 & 13 & 21 & 14 & & Max vs. Min \\
\hline Min & 13 & 7 & 1 & -1 & -3 & -2 & 2 & 7 & 3 & $\mathrm{r}=0.378^{* *}$ & \\
\hline Difference & 11 & 12 & 12 & 8 & 8 & 9 & 11 & 14 & 11 & & \\
\hline
\end{tabular}

${ }^{1}$ See Table 1 footnote 2 for explanation of plant response class code. ${ }^{2}$ Each daily response value is a mean for 5 years over 50 sites. ${ }^{3}$ Percentage is the yearly total for a class divided by the total number of days (242) in the 8 months.

freezing days were masked in their 5-year means. The percentage varied among sites $(23.8 \%-35.8 \%)$ and months $(2.5 \%-20.4 \%)$.

\section{Discussion}

The previous study [8], resulted in preliminary findings that chilling production 
Table 3. Analysis of chilling temperatures (class b, $0^{\circ} \mathrm{C}-7.2^{\circ} \mathrm{C}$ ) frequency and duration of occurrences of daily max and min temperatures within the chilling range by months (Sep - April) over 5 years (2010-11-2014-15) and 11 sites $^{1}$.

\begin{tabular}{|c|c|c|c|c|c|c|c|c|c|c|c|}
\hline \multicolumn{12}{|c|}{ Mean duration of daily max and min temperatures within chilling range } \\
\hline Max temp consecutive days & Sep & Oct & Nov & Dec & Jan & Feb & Mar & Apr & Total & Weighted & Days $\% 2$ \\
\hline 1 & 0 & 0.3 & 1.3 & 1.2 & 1.8 & 1.3 & 1.4 & 0.1 & 7.4 & 7.4 & 3.0 \\
\hline 2 & 0 & 0 & 0.7 & 1.1 & 1.8 & 1.1 & 1.5 & 0 & 6.2 & 12.4 & 5.1 \\
\hline 3 & 0 & 0 & 0.2 & 0.6 & 0.5 & 0.6 & 0.5 & 0 & 2.4 & 7.2 & 3.0 \\
\hline 4 or more & 0 & 0 & 0.4 & 1.2 & 1.3 & 1 & 0.2 & 0 & 4.1 & 16.4 & 6.8 \\
\hline Total & 0 & 0.3 & 2.6 & 4.1 & 5.4 & 4 & 3.6 & 0.1 & 20.1 & 43.4 & 17.9 \\
\hline Min temp consecutive days & Sep & Oct & Nov & Dec & Jan & Feb & Mar & Apr & Total & Weighted & Days \%2 \\
\hline 1 & 0.9 & 1.5 & 3.1 & 2.4 & 2.8 & 2.1 & 2.7 & 2.2 & 17.7 & 17.7 & 7.3 \\
\hline 2 & 0.5 & 0.9 & 1.3 & 1.2 & 0.9 & 1.4 & 1.8 & 1.5 & 9.5 & 19 & 7.8 \\
\hline 3 & 0.2 & 0.5 & 0.9 & 0.9 & 0.4 & 0.3 & 0.8 & 0.7 & 4.7 & 14.1 & 5.8 \\
\hline 4 or more & 0.1 & 1.6 & 0.9 & 0.6 & 0.2 & 0.4 & 0.8 & 0.7 & 5.3 & 21.2 & 8.8 \\
\hline Total & 1.7 & 4.5 & 6.2 & 5.1 & 4.3 & 4.2 & 6.1 & 5.1 & 37.2 & 72 & 29.8 \\
\hline Combined temp days & Sep & Oct & Nov & Dec & Jan & Feb & Mar & Apr & Total & Weighted & Days \%2 \\
\hline 1 & 0.9 & 1.8 & 4.4 & 3.6 & 4.6 & 3.4 & 4.1 & 2.3 & 25.1 & 25.1 & 10.4 \\
\hline 2 & 0.5 & 0.9 & 2 & 2.4 & 2.6 & 2.5 & 3.3 & 1.5 & 15.7 & 31.4 & 13 \\
\hline 3 & 0.2 & 0.5 & 1.1 & 1.5 & 0.9 & 0.9 & 1.2 & 0.7 & 7 & 21.3 & 8.8 \\
\hline 4 or more & 0.1 & 1.6 & 1.3 & 1.9 & 1.5 & 1.4 & 1 & 0.7 & 9.5 & 37.6 & 15.5 \\
\hline Total & 1.7 & 4.9 & 9 & 9.3 & 9.6 & 8.2 & 9.7 & 5.2 & 57.3 & 115.4 & 47.7 \\
\hline
\end{tabular}

${ }^{1}$ Data are based upon 11 sites (Table 1, numbers $1,5,10,15,20,25,30,35,40,45,50$ ). ${ }^{2}$ Percentage of days equals number observed divided by number of days (242) in the 8-month period.

Table 4. Number of days within months (December through April) in which one or more freezing temperatures (Class c) occurred among the 5 years but were masked by positive temperatures included within the mean.

\begin{tabular}{|c|c|c|c|c|c|c|c|}
\hline Site $^{1}$ & Dec & Jan & Feb & Mar & Apr & Total & $\%$ of days ${ }^{2}$ \\
\hline 1 & 16 & 4 & 8 & 18 & 6 & 52 & 34.4 \\
\hline 5 & 10 & 2 & 2 & 23 & 15 & 52 & 34.4 \\
\hline 10 & 10 & 1 & 0 & 23 & 6 & 40 & 26.5 \\
\hline 15 & 14 & 3 & 6 & 17 & 5 & 43 & 28.4 \\
\hline 20 & 17 & 4 & 0 & 17 & 0 & 38 & 25.2 \\
\hline 25 & 7 & 1 & 1 & 21 & 6 & 36 & 23.8 \\
\hline 30 & 12 & 2 & 4 & 22 & 14 & 54 & 35.8 \\
\hline 35 & 14 & 3 & 0 & 22 & 14 & 53 & 35.1 \\
\hline 40 & 17 & 5 & 0 & 18 & 1 & 41 & 27.2 \\
\hline 45 & 5 & 1 & 3 & 22 & 1 & 45 & 29.8 \\
\hline 50 & 14 & 2 & 7 & 22 & 6 & 51 & 33.8 \\
\hline Mean & 12.4 & 2.5 & 2.8 & 20.4 & 6.7 & 44.9 & $30.40 \%$ \\
\hline
\end{tabular}

${ }^{1}$ Data are based upon 5 months 11 sites taken from the 50 included in the study. ${ }^{2}$ Percentage of days equals number observed divided by number of days (151) in the 5-month period.

over 5 years and 50 sites consistently exceeded chilling requirements for perennial fruit crops commonly grown in Kentucky. This margin could provide a buf- 
fer of early protection against expected weather warning and its negative effect on chilling production. The purpose in extending the study was to explore some alterations of the temperature metrics utilized in the Chilling Hours Model and, thereby, enhance understanding of chilling conditions. A main objective was to ascertain effects of dividing daily air temperature into plant functional classes on chilling production.

Initiation of the chilling process depends upon temperatures between $0^{\circ} \mathrm{C}$ $7.2^{\circ} \mathrm{C}$ [10]. For the 50 sites in the present study, the percentage of days in the chilling range was $59.4 \%$ composed of $1.2 \%$ homo bb and $58.2 \%$ hetero $(36.2 \%$ $\mathrm{ab}, 22.0 \% \mathrm{bc}$ ). Total days in which a max or min temperature was included in the chilling range was approximately 115 (Table 3 ). However, these calculations are based only upon max and min and do not include other daily temperature between these extremes. Including frequencies and durations of consecutive days of chilling temperatures revealed that $25.1 \%, 31.4 \%, 21.3 \%$, and $37.6 \%$ of the chilling periods were for $1,2,3$, and 4 or more days; respectively. Since the common winter chill models are based upon the accumulation of hourly temperature, the chilling process must be able to circumvent gaps in temperature conditions. Furthermore, average chilling hours' production by sites (Table 1) was 1557 which by definition equals the number of clock hours or about 65 twenty-four hour days. It appeared more likely that the critical temperature initiated the chilling process which continued intermittingly as temperature permitted. This explanation is further supported by the homo bb being lower than the hetero, $a b$ and $a c$, and by ab being greater than ac. These observations may provide support for the Dynamic Model including a two-step process initiated by cooler weather and continuing under warmer temperature.

Different temperature metrics were compared for their influence on chilling. The highest hourly temperatures for each day in the month were averaged to get the max; the lowest hourly temperature for each day was averaged to get the $\min$. These, temperatures were used to study relationships between max and min temperature with chilling temperature (Table 3). Of the total 115.4 days in which max and min temperatures were included in the chilling range, $62.4 \%$ were $\min$ and $37.6 \%$ were max. Thus, min contributed nearly twice that of $\max$ to chilling temperature. These findings support the emphasis on max and min indices as reported by other researchers [6] stated that daily max and min temperatures had major impact on plant growth and development. Lobell et al. (2007) [11] concluded that quantities such as chill hours that are used in models to predict climate changes are more related to daily max and min when used separately than when averaged.

In the present study, max and min temperatures were based on 5-year means. Since a mean is a single value that brings unequal quantities together into a best fitting number, it is possible that the impact of a critical component could be lost. Approximately $30 \%$ of freezing temperatures (class c) for individual years were masked by above freezing temperature in the 5-year means. This outcome 
is especially critical for reporting of multiple-year predictions in chilling studies. A single extreme weather condition such as a freezing temperature can kill developing buds.

The greater association of min than max temperatures within the chilling range (Table 3) is consistent with results of other reported studies. Vos et al. 2004 [12] determined that min temperatures over global land areas increased approximately two times as fast as max temperatures since 1950. During this time period in California, LaDochy et al. 2007 [13] observed that min increased faster than max temperatures. Vincent, et al. 2005 [14] compiled weather summary data from eight South American countries showing that global warming effects can be attributed to rising min temperatures that have increased faster than max or mean temperatures. In summary, these results indicate that global warming has greater negative impact on min than on max or mean temperature, whereas, chilling has a higher positive association with min than with max or mean temperature. Thus, as has been experienced, warming has a negative effect on chilling.

\section{Conclusion}

Continued investigation into relationships between chilling and temperature is warranted in view of the warming that has occurred and the unequivocal predictions (IPCC 2014) [15] that the warming trend is continuing. A more direct focus on temperature/chilling relationships was possible by using daily max and min rather than mean temperature and by dividing daily temperatures into plant functional classes: growing, chilling, and freezing. Within the chilling class, more min than max temperatures were associated with chilling. For studies involving temperatures fluctuating around $0^{\circ} \mathrm{C}$, the use of means may mask injurious freezing temperature. The smaller number of hours in the chilling class compared to the total number of chilling hours produced, may support the Dynamic Chilling Model which postulates a two-step process initiated by cooler and increased by warmer temperature. However, further research on initiation and duration of chilling conditions is necessary.

\section{Acknowledgements}

Appreciation is expressed to Dr. Stuart A. Foster, State Climatologist for weather data provided by the Kentucky Climate Center through Kentucky Mesonet. Special thanks are extended to Charles E O'Connor for technical assistance with data processing. Support of the Departments of Agriculture and Public Health, the College of Science and Engineering, the Office of Research and Creativity, and the University Provost is greatly acknowledged. Response to the reviewer's comments added value to the manuscript.

\section{References}

[1] Knight, T.A. (1801) Account of Some Experiments on the Ascent of the Sap in 
Trees. Philosophical Transactions of the Royal Society of London, 91, 333-353. https://doi.org/10.1098/rstl.1801.0017

[2] Chandler, W.H., Kimball, M.H., Philp, G.L., Tufts, W.P. and Weldon, G.P. (1937) Chilling Requirements for Opening of Buds on Deciduous Orchard Trees and Some Other Plants in California. Bul. 611, Agricultural Experiment Station, Berkeley, California.

[3] Luedeling, E., Zhang, M. and Girvetz, E.H. (2009) Climatic Changes Lead to Declining Winter Chill for Fruit and Nut Trees in California during 1950-2099. PLOS One, 4, e6166. https://doi.org/10.1371/journal.pone.0006166

[4] Luedeling, E., Zhang, M., McGranahan, G. and Leslie, C. (2009) Validation of Winter Chill Models Using Historic Records of Walnut Phenology. Agriculture and Forest Meteorology, 149, 1854-1864.

https://doi.org/10.1016/j.agrformet.2009.06.013

[5] Luedeling, E. and Brown, P.H. (2011) A Global Analysis of the Comparability of Winter Chill Models for Fruit and Nut Trees. International Journal of Biometeorology, 55, 411- 421. https://doi.org/10.1007/s00484-010-0352-y

[6] Wilkins, P. and Singh, U. (2001) A CODE-Level Analysis for Temperature Effects in the CERES Models. Resource Development Division, International Fertilizer Development Center (IFDC).

[7] Easterling, D.R., Horton, B., Jones, P.D. and Peterson, T.C. (1997) Maximum and Minimum Temperature Trends for the Globe. Science, 277, 364-367.

https://doi.org/10.1126/science.277.5324.364

[8] Xue, Y., Adigarla, S.P., Seethi, V.S.R. and Gray, E. (2016) Assessing Chilling Conditions by Sites and Years for Perennial Fruit Production in Kentucky. American Journal of Plant Sciences, 7, 1407-1414. https://doi.org/10.4236/ajps.2016.710134

[9] Steel, R.G.D. and Torrie, J.H. (1980) Principles and Procedures of Statistics. 2nd Edition, McGraw-Hill, Inc., New York.

[10] Baldocchi, D. and Wong, S. (2007) Accumulated Winter Chill Is Decreasing in the Fruit Growing Regions of California. Climate Change, 87, S153-S166. https://doi.org/10.1007/s10584-007-9367-8

[11] Lobell, D.B., Bonfils, C. and Duffy, P.B. (2007) Climate Change Uncertainty for Daily Minimum and Maximum Temperatures: A Model Inter-Comparison. Geophysical Research Letters, 34, 1-5. https://doi.org/10.1029/2006GL028726

[12] Vose, R.S., Easterling, D.R. and Gleason, B. (2005) Maximum and Minimum Temperature Trends for the Globe: An Update through 2004. Geophysical Research Letters, 32, L23822. https://doi.org/10.1029/2005GL024379

[13] LaDochy, S., Medina, R. and Patzert, W. (2007) Recent California Climate Variability: Spatial and Temporal Patterns in Temperature Trends. Climate Research, 33, 159-169. https://doi.org/10.3354/cr033159

[14] Vincent, L.A., et al. (2005) Observed Trends in Indices of Daily Temperature Extremes in South America 1960-2000. Journal of Climate, 18, 5011-5023. https://doi.org/10.1175/JCLI3589.1

[15] IPCC (2014) Climate Change 2014: Synthesis Report. IPCC, Geneva. 